\title{
Intensification Dissolved Air Flotation Treatment of Oil-Containing Wastewater
}

\author{
Anton Andreevich Eskin ${ }^{1}$, Gennady Aleksandrovich Zakharov ${ }^{1}$, Nadezhda Sergeevna Tkach ${ }^{1} \&$ Ksenia \\ Vasilievna Tsygankova ${ }^{1}$ \\ ${ }^{1}$ Far Eastern Federal University (FEFU), Vladivostok, Russian Federation \\ Correspondence: Eskin Anton Andreevich, ul. Karbysheva d. 38, kv. 21, 690089 Vladivostok, Russian \\ Federation. Tel: 7-953-220-0658. E-mail: eskin.aa@dvfu.ru
}

Received: December 15, 2014

Accepted: December 20, 2014

Online Published: March 25, 2015

doi:10.5539/mas.v9n5p114

URL: http://dx.doi.org/10.5539/mas.v9n5p114

\begin{abstract}
The paper is devoted to the oil-containing water treatment by dissolved air flotation. Patents search revealed trends in the dissolved air flotation devices development. A method for increasing the treated fluid aeration by its dispersion at excess pressure is offered.

The electrolyte influence on the flotation extraction efficiency is researched. The change in electrolyte concentration influences the bubble coalescence degree, as well as the charge on the particle and the bubble. It is shown that an increase in electrolyte concentration can increase the flotation treatment efficiency. At that, a cheap source of electrolytes is by-products of different processes.

In addition, the paper presents data from the regulations in force in the territory of the Russian Federation, on the maximum permitted concentrations of oil products in wastewater. The advantages of dissolved air flotation in comparison with other types of flotation extraction are shown. This paper may be useful to engineers and scientists, whose work involves oil-containing water treatment.
\end{abstract}

Keywords: bubble, coalescence, coagulation, maximum permitted concentration, oil products, aeration, heterocoagulation

\section{Introduction}

More and more attention is paid to environmental protection every year, because according to the Decree of the President of the Russian Federation (RF Presidential Edict No. 899 as of 07.07.2011), sustainable environmental management, including the technology of monitoring and forecasting the state of the environment, prevention and elimination of pollution, is one of the priorities of the Russian Federation development.

Oil products contained in wastewater of different enterprises are among the most common pollutants. Existing regulations set strict requirements on the maximum permissible concentration (MPC) of oil products in wastewater (Table 1).

Table 1. MPC for oil products in wastewater

\begin{tabular}{lcl}
\hline \multicolumn{1}{c}{ Water body type } & $\begin{array}{c}\text { MPC rate, } \\
\mathrm{mg} / 1\end{array}$ & \multicolumn{1}{c}{ Normative document } \\
\hline $\begin{array}{l}\text { Drinking and cultural and community purpose } \\
\text { Fishery ponds }\end{array}$ & 0.1 & $\begin{array}{l}\text { Hygienic standard 2.1.5.1315-03, 2003 } \\
\text { Wederal Agency for Fisheries Edict No. 20 } \\
\text { of 18.01.2010 }\end{array}$ \\
$\begin{array}{l}\text { Rules of admission industrial of wastewater } \\
\text { into the sewage system of settlements, 2011 }\end{array}$ \\
\hline
\end{tabular}

At the beginning of the XXI century, Russia observed considerable slowing down of polluted wastewater discharge (Izrael, 2013). This is due primarily to the unstable and inefficient operation of treatment facilities. A large number of industrial enterprises use simple mechanical methods for wastewater treatment - gravity thickening in the interceptors and oil traps with thin-layer elements. These treatment methods cannot provide the 
desired final oil products concentration. In this regard, the technological schemes of treatment facilities at industrial enterprises need to implement post-treatment device of oil-containing water.

One of the effective advanced treatment technologies is flotation. Flotation means the recovery process of hydrophobic particles (petroleum, oils, and fats) by sticking them with gas bubbles, which carry them to the surface in the form of a concentrated foam product. Thus, flotation is classified primarily on the mode of the gas bubbles enter the treated fluid volume (Table 2).

Table 2. Flotation treatment methods

\begin{tabular}{|c|c|c|c|}
\hline Flotation type & Description & Average bubble diameter $(\mu)$ & $\begin{array}{l}\text { Efficiency } \\
(\%)\end{array}$ \\
\hline Pneumatic & $\begin{array}{l}\text { Bubbles are formed by compressed air } \\
\text { dispersion in the porous or perforated } \\
\text { elements }\end{array}$ & $\begin{array}{l}1000- \\
10000\end{array}$ & $60-70$ \\
\hline Mechanical & $\begin{array}{l}\text { Bubbles are formed due to the mechanical } \\
\text { interaction of air jets and water flow in the } \\
\text { impeller flotation cell }\end{array}$ & $\begin{array}{l}500- \\
5000\end{array}$ & $60-70$ \\
\hline Jet-aeration & $\begin{array}{l}\text { Bubbles are formed as a result of dispersed } \\
\text { air entrained by impinging fluid jet }\end{array}$ & $\begin{array}{l}2000- \\
6000\end{array}$ & $60-75$ \\
\hline Electroflotation & $\begin{array}{l}\text { Bubbles are formed by electrolytic } \\
\text { decomposition of water with oxygen } \\
\text { evolution on the anode, and hydrogen } \\
\text { evolution on the cathode. }\end{array}$ & $50-100$ & Up to 90 \\
\hline Dissolved air flotation & $\begin{array}{l}\text { Bubbles are separated from the fluid by } \\
\text { changing the conditions of solubility, } \\
\text { especially at pressure decrease. }\end{array}$ & $20-200$ & Up to 92.5 \\
\hline
\end{tabular}

At advanced treatment of oil-containing water in the form of a stable emulsion, oil products particle size is on average 2-8 $\mu$. Treatment efficiency reaches the maximum level when the bubble diameter is comparable to the particle diameter. The smallest diameter of the bubble can be obtained by the air separation from the fluid by reducing the pressure over its surface. In addition, according to the theory by Gibbs, the emergence of a new stage requires formation centres, so bubbles are much more likely to be allocated directly at the oil products particles, which also increases the dissolved air flotation efficiency (Perepelkin and Matveev VS, 1979)

Today, the dissolved air flotation method is used both for treating wastewater containing various contaminants, and for enrichment of deposits.

Despite the fact that the flotation is actively used in industry since the middle of last century, today this process is being actively studied. Along with the research areas of great fundamental importance for science (research of the nucleation and bubble surfacing process, particles and bubbles heterocoagulation simulation), there are areas that are of practical interest to improve the treatment efficiency. This paper provides a brief overview of current trends in the intensification of devices implementing dissolved air flotation method, as well as the electrolytes influence on the flotation recovery efficiency. Practical original solutions in these areas are offered.

\section{Methodology}

To determine trends in dissolved air flotation devices, the patents search resulted in the analysis of more than 120 patents from 20 countries. The information sources included the following:

abstract database of inventions of the federal executive authority on intellectual property of the Russian Federation in Russian language - RUPAT (http://www1.fips.ru/);

full-text databases on inventions of the European Patent Office in English language (http://ep.espacenet.com/);

full-text databases on inventions of the American Patent Office in English language (http://www.uspto.gov/).

Classification headings of search are defined based on exclusion of finding the desired information beyond the boundaries of the search areas. The search retrospective included 15 years. 
In order to research the electrolyte concentration influence on the flotation extraction efficiency, an analytical review of the scientific and technical literature was carried out. The sources of information mainly comprised of full-text database of scientific data - ScienceDirect (http://www.sciencedirect.com/) and Scientific Electronic Library - eLIBRARY (http://elibrary.ru/).

\section{Results}

Traditional dissolved air flotation is made as follows (Patent CN No. 2633859, 2004; Patent AT No. 410405, 2003). Air is supplied before the pump pumping treated fluid. Then this air is mixed with the treated fluid in the pump. The resulting water-air mixture is fed into a special pressure vessel (saturator), where it is maintained for some time (3-5 minutes) complete air dissolution. Compressed air can be fed directly into the pressure vessel, while the dissolution time shall be increased. Fluid saturated at the excess pressure is directed through the reducing valve to the flotation chamber under atmospheric pressure. There due to the sharp reduction of pressure, bubbling occurs with subsequent flotation of emulsified oil products. The disadvantage of this method is the periodicity of the process, caused by the need of time on the complete air dissolution. In case of non-compliance with the saturation time, part of the air can remain in the form of relatively large bubbles reducing flotation efficiency.

Patents search resulted in three main areas of dissolved air flotation devices intensification (Figure 1).

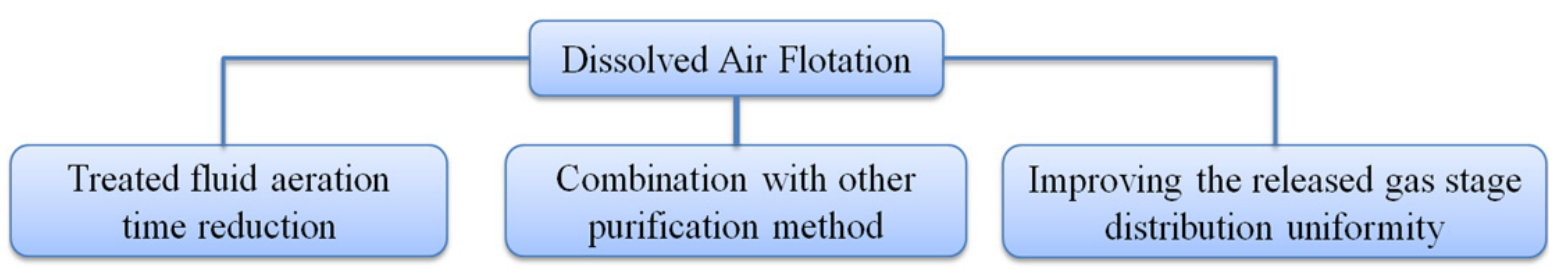

Figure 1. Modern dissolved air flotation development trends

One of the main development trends is to reduce the treated fluid aeration time.

In the device (Patent KR No. 200191 790, 2000), the water in the pressure vessel, located in the flotation cell centre, passes through the water-air ejector. Thus, it is said that due to the high flow turbulence, fluid is saturated before it is supplied to the pressure tank.

To reduce the aeration time, it is possible to use a pressure vessel with a partition made of a porous material (Patent RU No. 2386590). Air is fed under pressure of 0.5-0.6 MPa from one of the partition sides, and the adjacent cavity receives the water with 0.3-0.4 MPa pressure. Air, due to the pressure difference between the gas and fluid stages, passes through the porous partition of the saturator, leaving it in the form of tiny bubbles washed off the partition surface by the rotating water stream and immediately dissolves in water.

A device for performing dissolved air flotation, in which the pressure vessel is a pressure accumulator (Patent KR No. 100811 846, 2008) is known. The saturated fluid enters the space separated with a flexible membrane, wherein the hydrodynamic pressure increases its volume. After filling the pressure vessel, the water supply stops, and saturated fluid is forced by the membrane contraction. Then the process is repeated cyclically. The device (Patent CN No. 2516533, 2012) operates in a similar way, but the pressure vessel is formed as a container with a spring loaded transverse partition.

The device (Andreev et al., 2011) uses an electric discharge to create a water-air emulsion. Air is supplied to the treated fluid pumped under overpressure by the ejector. The resulting water-air mixture is supplied to the electrohydrodynamic device, wherein turbulent pulsations and electric field cause air dispersion, a part of which dissolves in the fluid, and another part forms bubbles with a diameter of 20-500 microns.

Saturation time is reduced using a special pump (http://www.daf-pump.com/). According to the manufacturer, if "DAF pump" is used, the pressure tank is not required - air dissolves in the pump itself. If considering pump design in more detail, then it is a vortex pump, which increases the transported flow energy through the accelerating fluid vortex rotation. In this case, the flow undergoes high turbulence, which results in air fragmentation and dissolution. However, at the same time, turbulence may lead to oil particles fragmentation, which has negative impact on the flotation extraction efficiency. 
The second dissolved air flotation intensification trend is improving the uniformity of the released gas stage distribution. In the devices (Patent US No. 008251228 2012; Patent FR No. 2808014, 2001; Patent PT No. 1483210, 2008)), flotation cell has a diamond-shaped or cone-shaped guides designed to stabilize bubbles and particles flow. In the devices (Patent MXPA No. 05010261, 2006; Patent CN No. 2402663, 2000), saturated fluid is evenly and radially distributed over the flotator lower part using a ring aerator. In the device (Patent KR No. 100797 197), the pre-saturated fluid is evenly distributed over the flotation cell bottom by a propeller blade. In the device (Patent CN No. 2835216, 2006), aerated water feed nozzles are evenly distributed over the flotation cell bottom. Even distribution of bubbles is achieved by the devices (Patent CN No. 2633859, 2004; Patent WO No. 0045961, 2000) with parabolic baffles.

The third trend is including treatment devices into the integrated framework. In this case, there are several possible association options - consistent dissolved air flotation, dissolved air flotation association with other methods in separate and a single device.

Dissolved air flotation may be carried out in a single device, but in several stages (Patent RU No. 2367622, 2009). At that, flotation cells connected consequently with each other, and a part of treated fluid is saturated with air and then supplied separately to each cell.

Today, there is a large number of patented methods including sequential wastewater treatment using various methods. (Patent RU No. 2264993, 2005; Patent WO No. 0105708, 2007; Patent TWI No. 300059, 2008; Patent KR No. 100799938, 2008; Patent CN No. 2818467, 2006; Patent CN No. 1792831, 2006; Patent JP No. 2000350984, 2000; Patent GR No. 1006201, 2008). Serially connected devices for mechanical and physical-chemical treatment allow obtaining the output water with very low residual oil products content, but complex application of these devices does not eliminate the disadvantages inherent in each separate device. In addition, such treatment facilities are of large size and require significant capital and operating costs.

Much more interesting is the association of several treatment methods in one device. In order to increase treatment degree, thin-film elements are added to the flotation cell of dissolved air flotation devices, used for separated oil products coalescence (Patent US No. 2013118988, 2013; Patent RU No. 2349553, 2009; Patent KR No. 100797197 2008; Patent CN No. 2458285, 2001; Patent JP No. 2001340847, 2001). Thus, there is a combination of the dissolved air flotation and thin layer sedimentation method.

Dissolved air flotation devices having the initial extraction of large particles due to their precipitation because of centrifugal force are also popular (Patent WO No. 0012220, 2000; Patent US No. 2012152124, 2000; Patent KR No. 200177217 2000; Patent CN No. 1470461, 2004). Such devices combine a pressure flotator with a skimmer hydrocyclone.

It is also possible to combine dissolved air flotation and ozonation. At that, direct fluid flotation with ozone may be carried out (Patent RU No. 2169708, 2001), or ozone treatment of the floated fluid (WO No. 02096808, 2002).

A combination of flotation and filtration is implemented in the devices (Patent GB No. 2356860, 2001; Patent EP No. 1944071, 2008; Patent DK No. 1494525, 2008; Patent JP No. 2000263038, 2000). Wastewater is treated by flotation pressure, and proceeds through the filter layer into the treated fluid chamber. More original is the solution in which the filtration load acts as a throttle valve (Patent RU No. 2469957). In this device, fluid saturated with excess pressure is passed through a particulate material (silica sand). After the passage of the initial filter layer, water pressure falls. Then air bubbles evolve, thus providing flotation. The disadvantage of this method is the periodicity of the process, caused by the need of time for the complete air dissolution.

Development of the device for oil containing water treatment by dissolved air flotation.

In order to intensify dissolved air flotation, this paper proposes a method for increasing the treated fluid aeration efficiency due to its dispersion in the pressure vessel under excess air pressure.

The device realizing this method works as follows (Figure 2). Treated fluid is supplied to the pressure vessel (1) under excess air pressure, the value of which can be controlled by the pressure regulator (8) via a hydraulic nozzle (4). The fluid is dispersed in the form of a torch, wherein the droplets have an extremely small size (less than $1 \mathrm{~mm}$ ), i.e. there is a large contact surface between the fluid and gas stages, whereby the fluid is almost instantaneously aerated. The walls of the pressure vessel are equipped with droplets-forming ring projection (10) which prevents the draining of fluid along the walls of the tank, thereby increasing the area and time of contact between the stages. Saturated fluid enters the aerated water distributors (18) located in the lower part of the flotation chamber (11) via the pipeline (17). The presence of several valves increases the uniformity of gas stage distribution over the flotation cell volume (11). Each distributor has a throttle valve (19), wherein the throttle 
valves are to be installed as close as possible to the flotation cell, since exactly such arrangement reduces the nucleus bubbles coalescence. When water saturated with excess pressure enters flotation cell through throttle valves, there is a sharp decline in pressure, which results in bubbling with subsequent formation of flotation sets, which float to the surface because of their low specific weight. The result is a layer of foam product comprising of floated impurities entering the ring manifold of the floated product (15), where the slope is used for gravity discharge through the floated product outlet pipe (16). Treated water is supplied to the ring collecting gap (12), where it is withdrawn through the treated water output pipe (13).

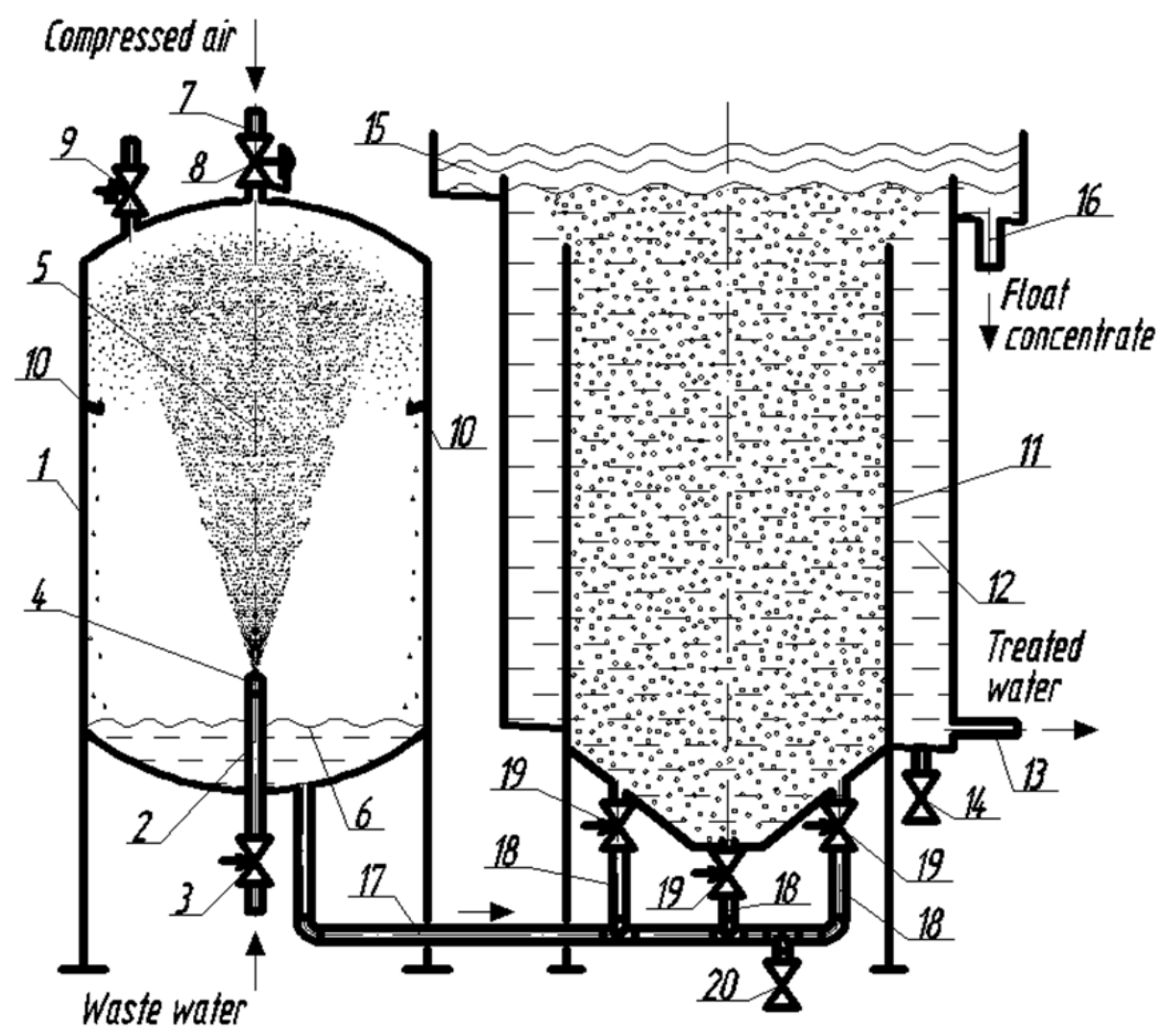

Figure 2. Dissolved air flotation method

The use of this device will reduce the time spent on saturation. The developed device is protected by an invention patent (Patent RU No. 2474538, 2012).

\section{Electrolyte concentration influence on the flotation extraction efficiency}

Particles size less than $100 \mu \mathrm{m}$ at advanced treatment of oil-containing water by dissolved air flotation. In this case, the contactless flotation mechanism is applied. The three-stage wetted perimeter is not formed between the particle and the bubble, but the particle is fixed by surface forces: molecular and electrostatic forces of the particle and bubble electric double layer (EDL) interaction.

During oil-containing water flotation, surface potential of the particle and bubble usually have the same sign, but differ in size, and the intermolecular force provides repulsion, while electrostatic force provides attraction at an extremely small distances and for certain values of $\zeta$-potentials.

To improve the treatment efficiency, various reagents, including surfactants, are used. Introducing cationic surfactants can significantly reduce the negative potential of the particle surface, which can lead to coagulation. Surfactants influence on the flotation separation efficiency was studied in papers (Watcharasing et al., 2009; Ramaswamy et al., 2007). However, the use of surfactants adversely affect the final composition of the treated fluid and requires additional operating costs.

One of the ways to improve the flotation extraction efficiency may be a change in the electrolyte concentration in the treated fluid. 
Experimental studies (Derjagin et al., 1986; Stahov, 1983) show that adding electrolytes not only increases the emulsified oil products extraction flotation rate, but also reduces their final concentration in water, at that the electrolytes force increases in the row of $\mathrm{NaNO}_{3}<\mathrm{NaCl}<\mathrm{CaCl}_{2}<\mathrm{AlCl}_{3}$.

Electrolyte influence nature is determined by the flotation treatment efficiency on the one hand, influence on the total electrolyte surface forces arising between the bubble and the particle, and influence on the bubble size on the other hand.

\section{Electrolyte influence on the bubble size}

The research of the nucleus bubble size in the presence of an electrolyte is provided in a large number of works (Fomin et al., 2009; Castillo et al., 2011; Craig, 2011; Horn et al., 2011; Kawahara et al., 2009; Quinn et al., 2014; Ribeiro et al., 2007; Ruenngam et al., 2008). Published experimental evidence indicates that the average bubble diameter decreases with increasing electrolyte concentration. The experimental results reflect only the quantitative characteristics of the processes and are submitted only for certain conditions. In this regard, there is a need to conduct a theoretical analysis of the electrolyte influence mechanism on the geometric and hydrodynamic parameters of bubbles in aqueous solution.

Film additional pressure $(\Delta \mathrm{P})$, determined by the law of Laplace (Erbil, 2006) influences the nucleus bubble size:

$$
\Delta P=\frac{2 \sigma_{g / f}}{r_{b}}
$$

where: $r_{b}$ is nucleus bubble radius, $m$

$\sigma_{\mathrm{g} / \mathrm{f}}$ is surface tension force, $\mathrm{n} / \mathrm{m}$.

Equation (1) shows that the nucleus bubble size depends on the surface tension of the fluid. Therefore, determination of the electrolyte influence degree on nucleus bubble size is reduced to determining its effect on the surface tension at the air-water boundary.

The paper (Kawahara et al., 2009) explains the average bubble diameter reduction by the fact that the surface tension of the fluid decreases with increasing electrolyte concentration. However, according to the classical adsorption theory, the increase of surface-inactive substances (SIS), which include various electrolytes, in the aqueous solution concentration, reduces the Gibbs free energy. At that, part of the SIS molecules get to the surface layer by diffusion and, having a surface tension larger than that of the pure solvent, provides a slight increase of the surface tension of the total solution (Slavchov, 2012).

Thus, the reduction in the average bubble diameter at adding into an aqueous electrolyte solution cannot be explained by the nucleus bubble diameter reduction caused by the change of the surface tension of the fluid.

Most researchers explain the reason for the diameter reduction of average bubbles allocated from a supersaturated solution by the electrolyte influence on the nucleus bubble size and the bubble coalescence stability.

\section{Electrolyte influence on the coalescence degree}

Coalescence is one of the most difficult processes for numerical calculation and mathematical modelling. This is because many parameters influence the coalescence efficiency - electrolyte concentration, its type, ph, temperature, pressure, bubbles approach velocity, bubbles initial size, fluid viscosity, surface tension, and others.

The theory of lyophobic colloids stability (systems with surface energy excess) is developed by Derjagin B. V. (Derjagin, 1986). The two main parameters influence the bubbles ability to coalescence - the surface forces and the fluid layer between the two gas phases.

The total surface force is made up of electrostatic and intermolecular forces. Electrostatic force creates a positive value of the disjoining pressure $(\mathrm{P})$ and prevents coalescence. The intermolecular interaction strength creates a negative component of the disjoining pressure, ensuring bubbles convergence. Based on the experimental data, thin films in solutions containing no surfactants become unstable when approaching at a distance of less than 50 $\mathrm{nm}$. The intermolecular interaction strength becomes comparable to the film capillary pressure at this distance. Furthermore, any fluctuation in film thickness leads to an increase in the negative component of the disjoining pressure and, as a result, to the film rupture and bubbles fusion.

The second factor affecting the coalescence degree is the presence of the displacing fluid flow between the two approaching bubbles. Hydrodynamic forces resulting from its presence, as well as the cumulative effect of the surface and capillary forces, distort the bubble shape at the contact point. Thus, strain deepening can form in the bubbles contact point. 
One of the most important issues arising in the analysis of the displacement current is the mobility of the film at the stages borders. If the two phases have the same viscosity, the surface layer at their boundary will not experience friction and the surface will be fully mobile. However, water and air viscosities differ by more than 10 times. Due to this fact, the surface shall be either totally or partially fixed. Due to the different approaches to the film mobility, there are different bubbles interaction models.

The paper (Horn et al., 2011) attempted to combine different models into a single theory to reflect coalescence mechanisms depending on the two main parameters - the bubbles convergence rate and the electrolyte concentration. The study resulted as follows: a chart was compiled in the logarithmic coordinates showing the possibility of gas bubbles coalescence at different electrolyte concentration and convergence rate. According to the data presented above a certain electrolyte concentration, the bubbles coalescence efficiency is reduced.

Theoretical explanation for coalescence time reduction in the presence of electrolytes is represented in (Prince et al., 1990). If considering the two colliding bubbles model which surface is movable, then during the approximation, a displacement flow is formed between them and is directed radially from the axis. Evenly distributed flow over the entire surface leads to gas weight transfer inside the bubble and to the creation of a new concave surface near the central axis. At that, the newly created surface will have a higher surface energy because the existing surface ions are present in an equilibrium state. The resulting difference in surface tension creates a tangential motion of the bubble surface preventing fluid escape from the deepening, thereby preventing the coagulation. As the electrolyte concentration increases, the difference between the newly formed surface energy and the energy of the existing one is thereby increasing, which ultimately leads to increased tangential efforts directed to slow down the fluid flow. Electrolyte critical concentration $\left(C_{c r}\right)$ above which the coalescence rate can be based on, can be evaluated based on the following functional connection:

$$
C_{c r}=1,18 v\left(\frac{B \sigma}{r_{b}}\right)^{1 / 2} R T^{-2},
$$

where $v$ is the number of ions obtained at dissociation, $B$ is the Hamaker's constant value, $\sigma$ is the surface tension, $r_{b}$ is the bubble radius, $R$ is the gas constant value, $T$ is the temperature, $g$ is the surface activity.

\section{Electrolyte effect on the $\zeta$-potential}

Simultaneously with the surface tension increase, the addition of an electrolyte is capable of changing particle and bubble charges magnitude defined by the $\zeta$-potential value (Leroy et al., 1990). The EDL thickness at the introduction of supporting electrolyte (not able to complete the colloidal particles crystalline grid construction) is reduced, thus reducing the $\zeta$-potential. It is proved that with increasing amounts of introduced electrolytes, the colloidal system can go into isoelectric state $(\zeta=0)$. Under this condition, the total attraction force between the particle and bubble is capable of taking positive values, and the heterocoagulation probability is at its maximum level.

The paper (Moreva et al., 2011) researched the sulphate lignin aqueous dispersions aggregate stability in $\mathrm{NaCl}$ and $\mathrm{CaCl}_{2}$ solutions by filtration through track membranes. Introduction of salts leads to improved efficiency delay of sulphate lignin, which becomes significantly higher in the case of $\mathrm{CaCl}_{2}$. These results are related to the EDL compression and are consistent with the theory presented above.

Changing the $\zeta$-potential of an oil droplet in water by adding sodium carbonate is researched in the paper (Ashrafizadeh et al., 2012). According to the obtained data, with increasing concentration of $\mathrm{Na}_{2} \mathrm{CO}_{3}$ from 200 ppm to $12,000 \mathrm{ppm}$, the $\zeta$-potential of oil droplets is reduced from $0.8 \mathrm{mV}$ to $0.2 \mathrm{mV}$.

The paper (Najafi et al., 2007) describes a method for determining the $\zeta$-potential value for a nanobubble released from the supersaturated electrolyte solution using laser electrophoresis. The $\zeta$-potential is increased with the increase in salt content, at that the electrolyte efficiency increases in the $\mathrm{NaCl}<\mathrm{CaCl}_{2}<\mathrm{Al}_{2}\left(\mathrm{SO}_{4}\right)_{3}$ row.

The results of experiments to determine the $\zeta$-potential of a bubble in the presence of surfactants and foaming agents are represented in the papers (Diya'uddeen et al., 2011; Elmahdy et al., 2008). Anionic polymers increase the negative bubble charge, while cationic polymers and non-ionic surfactants make it possible bubble's acquisition of a positive charge.

The research of calcium chloride and various coagulants effects on oil-containing fluid treatment efficiency is shown in the paper (Tong et al., 2013). It was revealed that the increase in the potassium chloride concentration in the treated fluid is capable of increasing the oil products extraction rate up to the level corresponding to the use of special flocculants (polyacrylamide and polyepichlorohydrindimethylamine) (Figure 6). 
The paper (Sokolović et al., 2009) researched the wastewater treatment from oil products by coagulation. According to the obtained results, the EDL value does not depend on the various electrolytes concentration in water, but on the dissolved oil products type. At that, the total water salt content, according to the authors, has virtually no effect on the treatment efficiency.

Thus, the majority of the experimental data on the electrolyte concentration effect on the $\zeta$-potential value of a particle and a bubble shows that with increasing electrolyte concentration in the treated fluid, the $\zeta$-potential of particles is reduced, while the $\zeta$-potential of bubbles increases. The combination of these two factors leads to an increase in effective heterocoagulation. Therefore, increasing oil-containing wastewater treatment degree shall be achieved by increasing fluid salinity be treated to a certain level.

\section{Discussion and Conclusions}

The paper presents an overview of the two directions for dissolved air flotation intensification - the development of treatment devices and the electrolyte influence on the treatment efficiency.

As a result of a patent search, the three trends in the dissolved air flotation devices development is revealed: increasing fluid saturation speed, increasing bubble distribution uniformity over a flotation cell, a combination based on the mechanical and physical and chemical treatment methods dissolved air flotation. Each of these areas present the most interesting technical solutions capable of intensifying the dissolved air flotation process. It shall be noted that the leader in the number of patent applications in the field of flotation treatment is China, but original and interesting devices are presented in patent applications from various countries. The presented trends and devices can be useful to select the direction of developing dissolved air flotation oil-containing water treatment devices structures.

The method comprising fluid dispersion with excess pressure solves the problem of reducing treated fluid aeration time. Despite the fact that this method will have higher energy costs as compared with the traditional one, it may open the possibility to improve the discharged wastewater quality. In addition to increasing fluid aeration speed, a large contact surface between the stages can intensify such decontamination processes as waste water ozonisation or UV irradiation. Typically, ozone wastewater treatment requires a contact tank providing a contact time of at least 10 minutes. In the case of adding ozone into the pressure vessel for fluid dispersion, the oxidation rate may increase and the contact time will decrease. This may eventually reduce the ozone consumption with increasing oxidation efficiency. Atomization may also intensify the ultraviolet disinfection. A disadvantage of the UV treatment is its ineffectiveness at high wastewater turbidity. Fluid atomization allows uniform UV-processing of the entire treated fluid volume. Thus, the developed method has great prospects. To date, a semi-industrial sample is under the production. It is aimed at the implementation of pilot studies.

Scientific papers devoted to the electrolytes effects on the bubble coalescence and particles and bubbles charges magnitude are analysed. It was found that the electrolyte concentration increase reduces the bubbles coalescence efficiency and the $\zeta$-potential of particles, but increases the $\zeta$-potential of bubbles. All these factors have a positive effect on the flotation extraction kinetics. At that, an almost free source of electrolytes is the by-products of various technological processes such as blowdown water from sodium cationic filters or brine obtained at sea water desalination. Despite the fact that, according to the present theoretical study, the flotation treatment effectiveness shall increase with increasing salinity fluid, a number of experimental studies does not confirm this There may be several explanations. According to the data (Haarhoff et al., 2013), sea water dissolves $26 \%$ less air than fresh water at the same temperature. It means, that at simultaneous increase in the flotation efficiency, quantitative efficiency decrease can be observed by reducing the number of bubbles. Also, the fact that the term "oil products" refers to an unstable oil composition mixture of substances, each having own coagulation ability, may also have certain influence. It is logical to assume that not all materials are equally responsive to changes in the electrolyte concentration.

The arguments mentioned above show that the promising research direction is the further study of particles and bubbles heterocoagulation process in the presence of electrolytes. The optimum electrolytes concentration for the flotation treatment shall be determined depending on the chemical composition and physical and chemical features of the treated fluid.

\section{Acknowledgments}

"The project was supported by the Scientific Fund of FEFU" grant No. 12-08-13023-m-18/13.

\section{References}

Andreev, S. Y., Grishin, B. M., Aleksejeva, T. V., \& Shirshin, I. B. (2011). New technology of reagentless floatation treatment of waste water containing oil products. Regional architecture and engineering, 1, 
$148-152$.

Ashrafizadeh, S. N., Motaee, E., \& Hoshyargar, V. (2012). Emulsification of heavy crude oil in water by natural surfactants. Journal of Petroleum Science and Engineering, 86-87, 137-143. http://dx.doi.org/10.1016/j.petrol.2012.03.026

Castillo, L. A., Ohnishi, S., \& Horn, R. G. (2011). Inhibition of bubble coalescence: Effects of salt concentration and speed of approach. Journal of Colloid and Interface Science, 356-1, 316-324.

Craig, V. S. J. (2011). Do hydration forces play a role in thin film drainage and rupture observed in electrolyte solutions. Current Opinion in Colloid \& Interface Science, 16-6, 597-600. http://dx.doi.org/10.1016/j.cocis.2011.04.003

Derjagin, B. V. (1986). Theory of stability of colloids and thin films. M.: Nauka.

Derjagin, B. V., Duhin, S. S., \& Rulev, N. N. (1986). Microflotation. M.: Himija.

Diya'uddeen, B. H., Ashri, W. D. W. M., \& Abdul, A. A. R. (2011). Treatment technologies for petroleum refinery effluents: A review. Process Safety and Environmental Protection, 89-2, 95-105. http://dx.doi.org/10.1016/j.psep.2010.11.003

Elmahdy, A. M., Mirnezami, M., \& Finch, J. A. (2008). Zeta potential of air bubbles in presence of frothers. Int. J. Miner. Process, 89, 40-43. http://dx.doi.org/10.1016/j.minpro.2008.09.003

Erbil, Y. (2006). Surface chemistry of solid and liquid interfaces. Oxford: Blackwell Publishing.

Federal Agency for Fisheries Edict No. 20 of 18.01.2010 (2010). Russian Newspaper, 5125.

Fomin, D. P., Morozov, D. S., \& Cygankova, K. V. (2009). To calculation of the quantitative features of the processes to jet aeration to fluids. Bulletin of Volgograd State University of Architecture and Civil Engineering Series. Civil Engineering and Architecture, 14, 170-175.

Hygienic standard 2.1.5.1315-03 (2003). Maximum permissible concentration (MPC) of chemicals in water bodies drinking and cultural and domestic water use. M.: Minzdrav.

Haarhoff, J., \& Edzwald, J. K. (2013). Adapting dissolved air flotation for the clarification of seawater. Desalination, 311, 90-94. http://dx.doi.org/10.1016/j.desal.2012.10.035

Horn, R. G., Lorena, A., \& Ohnishi, S. (2011). Coalescence map for bubbles in surfactant-free aqueous electrolyte solutions. Advances in Colloid and Interface Science, 14, 85-92. http://dx.doi.org/10.1016/j.cis.2011.05.006

Izrael, Y. A. (2013). Environmental pollution in Russian Federation at the beginning of the XXI century: Status and tendencies. Issue $2 . \quad$ M.: $\quad$ Rosgidromet. $\quad$ Retrieved from http://downloads.igce.ru/publications/Tendencies/Tendencies_Issue_2_2013.pdf

Kawahara, A., Sadatomi, M., \& Matsuyama, F. (2009). Prediction of micro-bubble dissolution characteristics in water and seawater. Experimental Thermal and Fluid Science, 33-5, 883-894. http://dx.doi.org/10.1016/j.expthermflusci.2009.03.004

KTM Series Pumps. (2014). Retrived from http:/www.daf-pump.com/

Leroy, P., Jougnot, D., Revil, A., Lassin, A., \& Azaroual, M. (2012). A double layer model of the gas bubble/water interface. Journal of Colloid and Interface Science, 388-1, 243-256. http://dx.doi.org/10.1016/j.jcis.2012.07.029

Moreva, Yu. L., Alekseeva, N. S., \& Chernoberezhskii, Y. M. (2011). Influence of NaOH, $\mathrm{HCl}, \mathrm{NaCl}$ and $\mathrm{CaCl}$ electrolytes on aggregation stability of aqueous craft lignin dispersion according to data of filtration through track membranes. Colloid Journal, 73-3, 363-367. http://dx.doi.org/10.1134/S1061933X11030082

Najafi, A. S., Drelich, J., Yeung, A., Xu, Z., \& Masliyah, J. (2007). A novel method of measuring electrophoretic mobility of gas bubbles. Journal of Colloid and Interface Science, 308-2, 344-350. http://dx.doi.org/10.1016/j.jcis.2007.01.014

Patent AT № 410405. (2003). Method and device for separating impurities from suspensions by flotation.

Patent CN № 1470461. (2004). Oil-containing sewage floatation cyclone coupling separation method.

Patent CN № 1792831. (2006). Process and apparatus for oil eliminating by pressure dissolved air floatation with nitrogen as gaseous source.

Patent CN № 2402663. (2000). Integrative clarification air floatation basin. 
Patent CN № 2633859. (2004). High efficiency air float machine.

Patent CN № 2633859. (2004). High efficiency air float machine.

Patent CN № 2818467. (2006). Re-using device for washing-car waste water.

Patent CN № 2835216. (2006). Vertical air floatation tank.

Patent CN №2458285. (2001). Eddy air-float integrated device.

Patent CN №2516533. (2002). Release.

Patent DK № 1494525. (2008). Method for the wastewater treatment in fish farming.

Patent EP № 1944071. (2008). Dissolved air flotation with filter system.

Patent FR № 2808014. (2001). Protein skimmer.

Patent GB № 2356860. (2001). Flotation system for fluid treatment.

Patent GR № 1006201. (2008). System for the removal of toxic heavy metals from shells.

Patent JP № 2000263038. (2000). Floatation equipment and circulation warm bath apparatus.

Patent JP № 2000350984. (2000). Method and apparatus for treating oil-containing waste water.

Patent JP № 2001340847. (2001). Aeration/separation apparatus for removing/separating algae, green algae, and red tide plankton.

Patent KR № 100797197. (2008). Dissolved air floatation system for treatment wastewater.

Patent KR № 100797197. (2008). Dissolved air floatation system for treatment wastewater.

Patent KR № 100799938. (2008). Apparatus for waste water treatment.

Patent KR № 100811846. (2008). Decanting unit with an air cylinder for controlling the operation thereof, and a wastewater processing apparatus employing the same.

Patent KR № 200177217. (2000). A floatation tank for water treatment.

Patent KR № 200191790. (2000). Waste water treatment by induced air.

Patent MXPA № 05010261. (2006). System and method of gas energy management for particle flotation and separation.

Patent PT № 1483210 (2008). Method and device for clarification of fluids, particularly water, loaded with material in suspension.

Patent RU № 2264993. (2005). Method for oil-containing wastewater treatment.

Patent RU № 2349553. (2009). Flotation plant.

Patent RU № 2386590. (2010). Method for wastewater treatment by flotation pressure.

Patent RU № 2469957. (2012). A method of wastewater treatment from car washes.

Patent RU № 2474538. (2013). Device for oil-containing wastewater treatment.

Patent RU №2169708. (2001). Method for wastewater treatment.

Patent RU №2367622. (2009). Multistage plant of flotation water treatment.

Patent TWI № 300059 (2008). Anaerobic biological wastewater treatment system and process.

Patent US № 008251228. (2012). Process and apparatus for adsorptive bubble separation.

Patent US № 2012152124. (2015). Combined degassing and flotation tank.

Patent US № 2013118988. (2013). Multistage daf-advanced oxidation system.

Patent WO № 0012220 (2000). Particle separating apparatus.

Patent WO № 0045961. (2000). Fluid conditioning system and method.

Patent WO № 0105708. (2001). A process and a plant for fluid treatment.

Patent WO № 02096808. (2002). Method for treatment of wastewater.

Perepelkin, K. E., \& Matveev, V. S. (1979). Gas emulsions. L.: Himija.

Prince, M. J., Michael, J. P., \& Blanch, H. W. (1990). Transition electrolyte concentrations for bubble coalescence. AIChE Journal, 36-9, 1425-1429. http://dx.doi.org/10.1002/aic.690360915 
Quinn, J. J., Maldonado, M., Gomez, C. O., \& Finch, J. A. (2014). Experimental study on the shape-velocity relationship of an ellipsoidal bubble in inorganic salt solutions. Minerals Engineering, 55, 5-10. http://dx.doi.org/10.1016/j.mineng.2013.09.003

Ramaswamy, B., Kar, D. D., \& De, S. (2007). A study on recovery of oil from sludge containing oil using froth flotation. Journal of Environmental Management, $150-154$. http://dx.doi.org/10.1016/j.jenvman.2006.08.009

RF Presidential Edict No. 899 of 07.07.2011 "On approval of the priority directions of development of science, technology and engineering in the Russian Federation and of the list of critical technologies of the Russian Federation. Retrieved from http://eng.kremlin.ru/news/2530

Ribeiro, C. P., \& Mewes, D. (2007). The effect of electrolytes on the critical velocity for bubble coalescence. Chemical Engineering Journal, 126-1, 23-33. http://dx.doi.org/10.1016/j.cej.2006.08.029

Ruen-ngam, D., Wongsuchoto, D., Limpanuphap, A., Charinpanitkul, T., \& Pavasant, P. (2008). Influence of salinity on bubble size distribution and gas-liquid mass transfer in airlift contactors. Chemical Engineering Journal, 141-1, 222-232. http://dx.doi.org/10.1016/j.cej.2007.12.024

Rules of admission industrial of wastewater into the sewage system of settlements. (2011). M.: Minzhilkomhozom.

Slavchov, R. I., \& Novev, J. K. (2012). Surface tension of concentrated electrolyte solutions. Journal of Colloid and Interface Science, 387- 1, 234-243. http://dx.doi.org/10.1016/j.jcis.2012.07.020

Sokolović, R. Š., Sokolović, S., \& Šević, S. (2009). Oily water treatment using a new steady-state fiber-bed coalesce. Journal of Hazardous Materials, 162, 410-415. http://dx.doi.org/10.1016/j.jhazmat.2008.05.054

Stahov, E. A. (1983). Treatment of oil-containing wastewater of enterprises of fuel oil storage and transportation. L.: Nedra,

Tong, K., Zhang, Y., \& Chu, P. K. (2013). Evaluation of calcium chloride for synergistic demulsification of super heavy oil wastewater. Colloids and Surfaces A: Physicochemical and Engineering Aspects, 419, 46-52. http://dx.doi.org/10.1016/j.colsurfa.2012.11.047

Watcharasing, S., Kongkowit, W., \& Chavadej, S. (2009). Motor oil removal from water by continuous froth flotation using extended surfactant: Effects of air bubble parameters and surfactant concentration. Separation and Purification Technology, 70-2, 179-189. http://dx.doi.org/10.1016/j.seppur.2009.09.014

\section{Copyrights}

Copyright for this article is retained by the author(s), with first publication rights granted to the journal.

This is an open-access article distributed under the terms and conditions of the Creative Commons Attribution license (http://creativecommons.org/licenses/by/3.0/). 